\title{
Poly(trimethylolpropane trimethacrylate) modified with esters derivatives of 3-phenylprop-2-en-1-ol
}

\author{
Marta Worzakowska ${ }^{1}$
}

Received: 10 March 2017 / Accepted: 19 December 2017 / Published online: 6 January 2018

(C) The Author(s) 2018. This article is an open access publication

\begin{abstract}
The main objective of this paper was to study the influence of the diesters derivatives of naturally occurring alcohol: 3-phenylprop-2-en-1-ol, on the thermal, viscoelastic and mechanical properties of bulk poly(trimethylolpropane trimethacrylate) [poly(TRIM)]. The bulk poly(TRIM) networks were obtained by mixing trimethylolpropane trimethacrylate with $0.5,1,2,3,5,10$ and 20 mass $\%$ of diesters and polymerized in the presence of 1.5 mass $\%$ of benzoyl peroxide in the temperature range from 50 to $80{ }^{\circ} \mathrm{C}$. Generally, bulk poly(TRIM) modified with esters derivatives of 3-phenylprop-2-en-1-ol was characterized by lower stiffness, lower glass transition temperature, lower thermal stability, lower hardness and heat deflection temperature values, and higher tensile strength and percentage elongation, especially for compositions containing higher diester content as compared to pure, bulk poly(TRIM).
\end{abstract}

Keywords Material testing - Mechanical properties - Thermal properties · Trimethylolpropane trimethacrylate (TRIM) . Esters of 3-phenylprop-2-en-1-ol

\section{Introduction}

Trimethylolpropane trimethacrylate (TRIM) is a water-insoluble, low-viscosity methacrylate monomer with a wide range of industrial applications. It has a high degree of functionality and low volatility, and thus, it is commonly applied as a reactive diluent in order to improve the strength, chemical resistance, heat resistance, hardness and weather resistance of many manufactured products. It forms both homopolymers and copolymers with various compounds, e.g. acrylic acid and its salts, amides, esters, methacrylates, acrylonitrile, maleic acid esters, vinyl acetate, vinyl chloride, vinylidene chloride, styrene, butadiene, unsaturated polyesters or drying oils [1-4]. The formed homopolymer: poly(trimethylolpropane trimethacrylate) [poly(TRIM)], is commonly used in the production of ultraviolet-curable inks, electron beam

Marta Worzakowska

marta.worzakowska@poczta.umcs.lublin.pl;

mworzako@op.pl

1 Department of Polymer Chemistry, Faculty of Chemistry, Maria Curie-Skłodowska University, Gliniana 33 Street, 20-614 Lublin, Poland irradiation-curable coatings, polymers and resins as a component of photopolymer and flexographic printing plates and photoresists and as an ingredient in acrylic glues, adhesives and anaerobic sealants. Additionally, it is used in the paper and wood impregnates, wire and cable extrusion, polymer-impregnated concrete, and polymer concrete structural composites [5-8]. Also, this multifunctional monomer with various monomers is generally applied in the production of porous microspheres suitable for chromatographic applications [9-11].

To improve the processing, performance and elasticity of polymer materials, the additives which make the material softer and more flexible are added [12-14]. The most generally applied plasticizers are phthalates and adipate esters, e.g. bis(2-ethylhexyl) phthalate, di-octylphthalate, diizodecyl phthalate, di- $n$-butylphthalate, butylbenzylphthalate, dioctyl adipate, bis(2-ethylhexyl) adipate. Also, stearates as plasticizers for lacquers and rubbers and esters of rosin are used [15-18]. Most of them have toxic properties for human, and recently, the studies on the new, nontoxic and biodegradable materials which could replace harmful plasticizers are developed [19]. In recent years, the intensive studies on the utilization of the epoxidized vegetable oils and biodiesel oils as plasticizers are conducted 
$[20,21]$. Also, eco-friendly plasticizers such as triacetin, tripropionin, triethyl citrate, tributyl citrate, tributyl 2-acetyl citrate and poly(ethylene glycol) of low molecular mass are known [22]. Recently, the studies on the utilization of diesters derivatives of 3-phenylprop-2-en-1-ol as suitable plasticizers for linear polymers such as polystyrene were performed [23].

The main objective of this paper is to study the possibility of using diesters derivatives of 3-phenylprop-2-en-1ol obtained in one-step polycondensation process of a stoichiometric ratio of 3-phenylprop-2-en-1-ol and chosen acidic reagent: succinic anhydride or sebacic acid as new plasticizers for cross-linked polymeric materials. The influence of the diesters concentration on the thermal, viscoelastic and mechanical properties of bulk poly(TRIM) networks has been studied and discussed.

\section{Experimental}

\section{Materials}

Diesters derivatives of 3-phenylprop-2-en-1-ol were obtained during catalysed esterification process of $2 \mathrm{~mol}$ of 3-phenylprop-2-en-1-ol (98\%, Fluka) with 1 mol of acidic reagent. As acidic reagents, succinic anhydride (99\%, Merck) and sebacic acid (98\%, Merck) were used. The reaction was carried out at $130{ }^{\circ} \mathrm{C}$, under reduced pressure. Butylstannoic acid (Arkema Inc., the USA) was used as a catalyst in the amount of 0.05 mass\% [24]. Trimethylolpropane trimethacrylate (TRIM) was from Aldrich. The vinyl monomer was washed with $10 \%$ solution of $\mathrm{NaOH}$ in order to remove an inhibitor, and then it was dried over anhydrous magnesium sulphate and drained off. Benzoyl peroxide was from POCh, Gliwice, Poland. Figure 1 presents the structure of the obtained diesters.
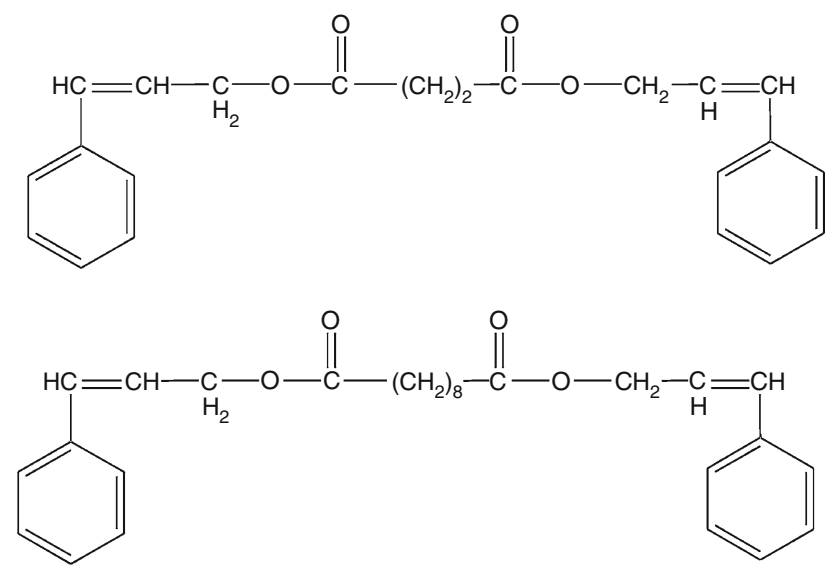

Fig. 1 Structure of diesters

\section{Polymerization procedure}

The polymerization process of components mixture containing from 0.5 to 20.0 mass $\%$ of diesters derivatives of 3-phenylprop-2-en-1-ol was carried out in the presence of benzoyl peroxide (used in the amount of 1.5 mass \%). Initially, the bulk polymerization process was performed at $50{ }^{\circ} \mathrm{C}$ and then the polymerization temperature was gradually increased to $80{ }^{\circ} \mathrm{C}$. The materials were kept at $80{ }^{\circ} \mathrm{C}$ until no additional post-curing signal was observed from DSC curves.

\section{Methods}

Differential scanning calorimetry analysis was performed with the use of a DSC 204 calorimeter, Netzsch, Germany, operating in a dynamic mode. DSC measurements were taken in $\mathrm{Al}$ pans with the pierced lid. Two dynamic scans of the samples $(10 \mathrm{mg})$ were performed at a heating rate of $10^{\circ} \mathrm{C} \mathrm{min}^{-1}$ under argon atmosphere $\left(25 \mathrm{~mL} \mathrm{~min}^{-1}\right)$. The first was from -20 to $200{ }^{\circ} \mathrm{C}$, and the second one from -20 to $550{ }^{\circ} \mathrm{C}$.

Dynamic mechanical analysis (DMA) was performed with the use of a Dynamic Mechanical Analyzer Q 800 TA Instruments, the USA, equipped with a double-cantilever device (support span of $35 \mathrm{~mm}$ ). The temperature scanning from -60 to $200-250{ }^{\circ} \mathrm{C}$ with a constant heating rate of $6{ }^{\circ} \mathrm{C} \min ^{-1}$ at an oscillation frequency of $10 \mathrm{~Hz}$ was conducted. The storage modulus $\left(E^{\prime}{ }_{20}^{\circ} \mathrm{C}\right), \tan \delta_{\max }$ and $\tan \delta_{\max }$ height were determined.

Heat deflection temperature (HDT) was evaluated using an HDT 3 VICAT apparatus, Ceast SpA, Italy. The rectangular profile of the samples $10 \mathrm{~mm}$ wide, $4 \mathrm{~mm}$ thick and $70 \mathrm{~mm}$ length was submerged in an oil bath and heated (heating rate $2{ }^{\circ} \mathrm{C} \mathrm{min}^{-1}$ ) from $20^{\circ} \mathrm{C}$ until the $2 \%$ deflection of the sample under a load of $1.8 \mathrm{MPa}$ occurred.

Hardness according to Brinell was determined by means of a hardness tester HPK, Germany. In this procedure, a steel ball of $5 \mathrm{~mm}$ diameter was hydraulically loaded on the material test surface with a load $(F)$ of $36.5 \mathrm{kgf}(0,357$, 942, $725 \mathrm{kN})$. The load was applied for $60 \mathrm{~s}$. Then, the resulting depression in $\mathrm{cm}$ was read. The hardness (HK) was calculated using the equation: $\mathrm{HK} \quad[\mathrm{MPa}]=F /$ $1.57 * h * 0.098066=F_{1} * 0.098066$, where $F$ is load in kgf, $h$-depression in $\mathrm{cm}$, and $F_{1}=\mathrm{F} / 1.57 *$ h.

Mechanical properties were examined using a strength machine, Zwick Roell Z010, Germany, for the following samples: $10 \mathrm{~mm}$ wide and $4 \mathrm{~mm}$ thick. Measurements were taken at room temperature. The cross-head speed was $2 \mathrm{~mm} \mathrm{~min}{ }^{-1}$. The initial grip separation was $50 \mathrm{~mm}$. The ultimate tensile strength $(\delta)$ and percentage elongation at break $(\varepsilon)$ were determined. 
Table 1 DSC data for cured materials containing dicinnamyl succinate

\begin{tabular}{lllll}
\hline Diester/wt $\%$ & $T_{\text {onset }} /{ }^{\circ} \mathrm{C}$ & $T_{\max 1}{ }^{\circ} \mathrm{C}$ & $T_{\text {end }} /{ }^{\circ} \mathrm{C}$ & $\Delta H_{1} / \mathrm{Jg}^{-1}$ \\
\hline 0 & 305 & 457 & 493 & 463.8 \\
0.5 & 302 & 451 & 495 & 446.6 \\
1 & 290 & 458 & 494 & 454.2 \\
3 & 270 & 454 & 495 & 486.8 \\
5 & 275 & 451 & 492 & 516.0 \\
10 & 270 & 445 & 490 & 532.5 \\
20 & 264 & 437 & 485 & 513.3 \\
\hline
\end{tabular}

Table 2 DSC data for cured materials containing dicinnamyl sebacate

\begin{tabular}{lllll}
\hline Diester/wt $\%$ & $T_{\text {onset }} /{ }^{\circ} \mathrm{C}$ & $T_{\max 1} /{ }^{\circ} \mathrm{C}$ & $T_{\text {end }} /{ }^{\circ} \mathrm{C}$ & $\Delta H_{1} / \mathrm{Jg}^{-1}$ \\
\hline 0 & 305 & 457 & 493 & 463.8 \\
0.5 & 300 & 454 & 493 & 451.2 \\
1 & 295 & 451 & 495 & 475.1 \\
3 & 295 & 450 & 495 & 497.7 \\
5 & 278 & 449 & 490 & 532.9 \\
10 & 270 & 445 & 496 & 544.7 \\
20 & 265 & 443 & 490 & 554.1 \\
\hline
\end{tabular}

Thermal analysis was performed on a STA 449 Jupiter F1, Netzsch, Germany, using $\mathrm{Al}_{2} \mathrm{O}_{3}$ crucibles and the sample mass ca. $10 \mathrm{mg}$. The analyses were performed under helium atmosphere $\left(25 \mathrm{~mL} \mathrm{~min}{ }^{-1}\right)$ in the temperature range of $40-800{ }^{\circ} \mathrm{C}$ and with a heating rate of $10{ }^{\circ} \mathrm{C} \mathrm{min}^{-1}$.

\section{Results and discussion}

Below the temperature of $200{ }^{\circ} \mathrm{C}$, no exo- or endothermic signals from the DSC results gathered for bulk poly(TRIM), and poly(TRIM) containing diesters derivatives of 3-phenylprop-2-en-1-ol were observed (Tables 1 and 2). It confirmed that the samples are highly cured and testified to the absence of free monomer. No evaporation of components of the compositions was observed. In addition, due to high conversion of double bonds in the prepared networks, there was a lack of the glass transition region in DSC curves. In DSC curves above temperatures of $300{ }^{\circ} \mathrm{C}$, one endothermic signal was indicated. It was directly connected with the decomposition process of the studied materials [25-27].

The characteristic values of DSC signal such as onset decomposition temperature ( $\left.T_{\text {onset }}\right)$, maximum peak temperature $\left(T_{\max }\right)$, end decomposition temperature $\left(T_{\text {end }}\right)$ and the enthalpy of decomposition $(\Delta H)$ are given in Tables 1 and 2. The presented data suggested that higher content of diesters had higher influence on the characteristic temperatures. The $T_{\text {onset }}$ and $T_{\max }$ were shifted to lower temperatures as the diester content increased, which might be due to the lower thermal stability of diesters than that of pure poly(TRIM). However, more differences were observed when compared to the values of the decomposition enthalpy. As the diester content increased, the enthalpy of the decomposition process of the materials gradually increased. It confirmed higher stability of the bonds existing in poly(TRIM)

Table 3 Viscoelastic and mechanical properties, hardness and heat deflection temperatures for cured materials containing dicinnamyl succinate

\begin{tabular}{llllllcc}
\hline Diester/mass $\%$ & $E^{\prime}{ }_{20}{ }^{\circ} \mathrm{C} / \mathrm{MPa}$ & $\tan \delta_{\max } /{ }^{\circ} \mathrm{C}$ & $\tan \delta_{\max }$ height & $\delta / \mathrm{MPa}$ & $\varepsilon / \%$ & $\mathrm{HK} / \mathrm{MPa}$ & $\mathrm{HDT} /{ }^{\circ} \mathrm{C}$ \\
\hline 0 & 3200 & 143 & 0.038 & 60 & 5 & 177 \\
0.5 & 3150 & 140 & 0.065 & 62 & 5 & 176 \\
1 & 3100 & 135 & 0.073 & 65 & 70 & 6 & 176 \\
3 & 2860 & 130 & 0.076 & 78 & 11 & 17 \\
5 & 2750 & 128 & 0.078 & 82 & 15 & 175 \\
10 & 2500 & 125 & 0.085 & 94 & 23 & 105 \\
20 & 2080 & 120 & 0.098 & 103 & 100 \\
\hline
\end{tabular}

Table 4 Viscoelastic and mechanical properties, hardness and heat deflection temperatures for cured materials containing dicinnamyl sebacate

\begin{tabular}{|c|c|c|c|c|c|c|c|}
\hline Diester/mass\% & $E_{20}^{\prime}{ }^{\circ} \mathrm{C} / \mathrm{MPa}$ & $\tan \delta_{\max }{ }^{\circ} \mathrm{C}$ & $\tan \delta_{\max }$ height & $\delta / \mathrm{MPa}$ & $\varepsilon / \%$ & $\mathrm{HK} / \mathrm{MPa}$ & $\mathrm{HDT} /{ }^{\circ} \mathrm{C}$ \\
\hline 0 & 3200 & 143 & 0.038 & 60 & 5 & 177 & 110 \\
\hline 0.5 & 3120 & 138 & 0.068 & 63 & 6 & 177 & 110 \\
\hline 1 & 2950 & 135 & 0.079 & 65 & 6 & 174 & 105 \\
\hline 3 & 2730 & 128 & 0.083 & 74 & 9 & 172 & 100 \\
\hline 5 & 2620 & 125 & 0.096 & 78 & 12 & 170 & 95 \\
\hline 10 & 2190 & 123 & 0.112 & 84 & 17 & 166 & 90 \\
\hline 20 & 2010 & 115 & 0.125 & 96 & 25 & 121 & 82 \\
\hline
\end{tabular}



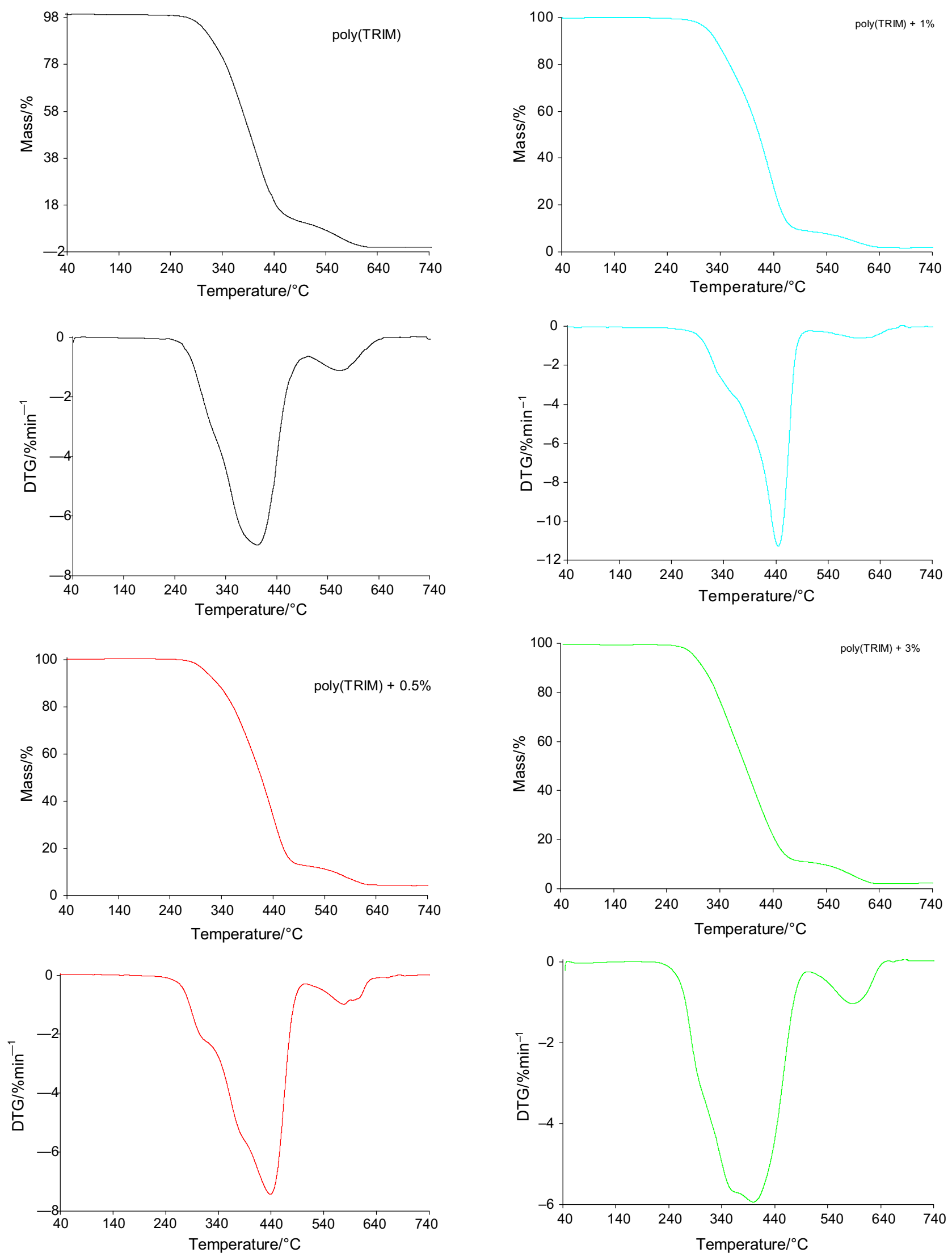

Fig. 2 TG and DTG curves of the prepared materials

Fig. 2 continued 

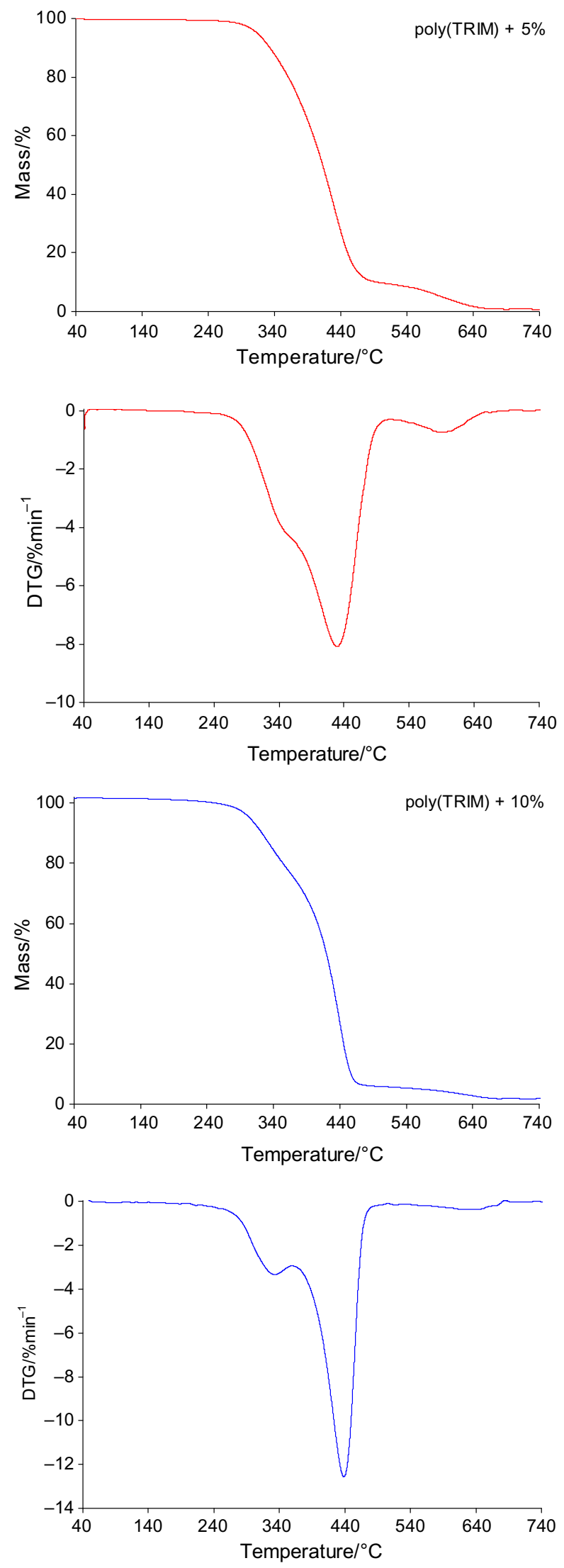

Fig. 2 continued
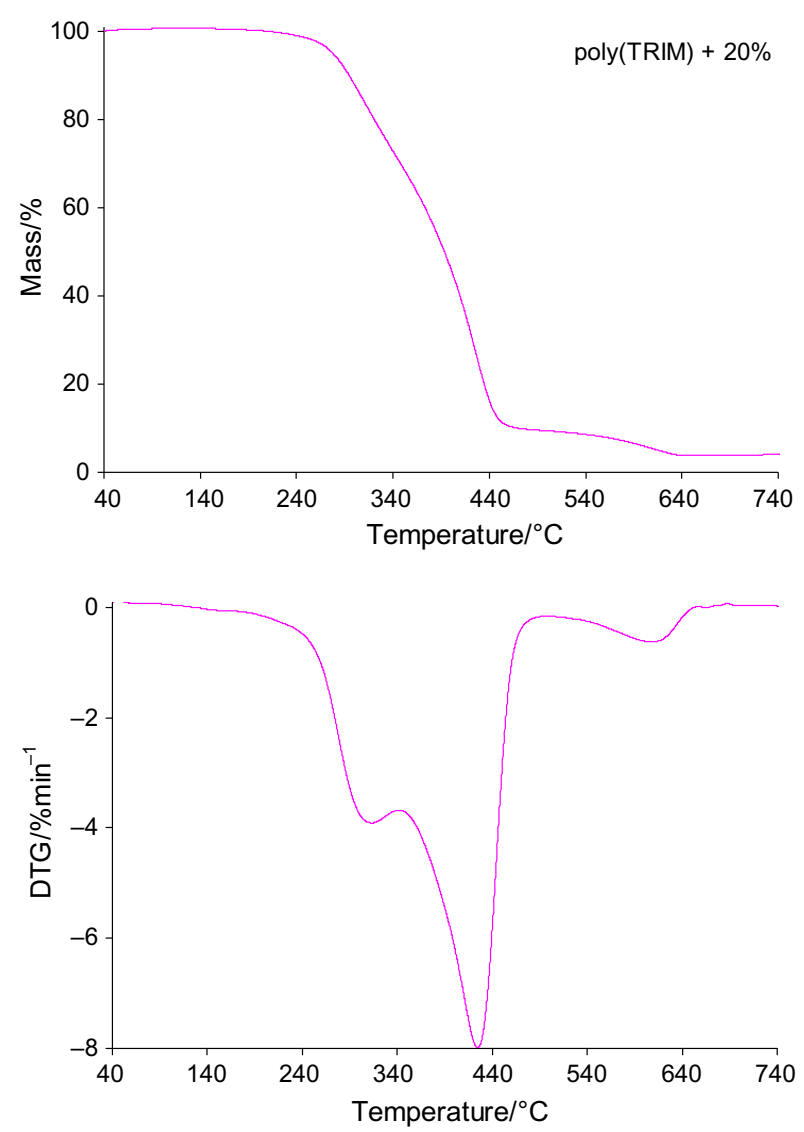

Fig. 2 continued

networks modified with esters derivatives of 3-phenylprop2-en-1-ol than in pure poly(TRIM).

The DMA data for obtained bulk poly(TRIM) materials are presented in Tables 3 and 4. The storage modulus $\left(E_{20}^{\prime}{ }^{\circ} \mathrm{C}\right)$ of pure, bulk poly(TRIM) $E_{20^{\circ} \mathrm{C}}^{\prime}$ was $3200 \mathrm{MPa}$. The storage modulus for poly(TRIM) modified with diesters was in the range from 3150 to $2080 \mathrm{MPa}$ for the materials containing dicinnamyl succinate and from 3120 to $2010 \mathrm{MPa}$ for the materials containing dicinnamyl sebacate (Tables 3 and 4). A decrease in $E_{20^{\circ} \mathrm{C}}^{\prime}$ values with increasing ester content is observed in the range of $0.5-20 \mathrm{wt} \%$ of diester. The highest changes in $E^{\prime}{ }_{20}{ }^{\circ} \mathrm{C}$ values are visible when the diester content is above 3 mass $\%$. The results indicated that poly(TRIM) modified with diesters was characterized by lower stiffness as compared to pure poly(TRIM). Also, the same trend was observed for the glass transition temperature $\left(T_{\mathrm{g}}\right)$ of the prepared polymers. $T_{\mathrm{g}}$ was evaluated as the maximum of $\tan \delta$ peak [28]. The $T_{\mathrm{g}}$ values decreased from $143{ }^{\circ} \mathrm{C}$ for pure, bulk poly(TRIM) to almost $120{ }^{\circ} \mathrm{C}$ for the materials containing 20 mass\% of dicinnamyl succinate and to $115{ }^{\circ} \mathrm{C}$ for the materials containing 20 mass $\%$ of dicinnamyl sebacate. In addition, the height of $\tan \delta_{\max }$, which was connected with the mobility of the resin molecules [29-32], increased as 
Table 5 TG and DTG data for cured materials containing dicinnamyl succinate

\begin{tabular}{|c|c|c|c|c|c|c|c|}
\hline Diester/mass \% & First weight loss/\% & $\mathrm{IDT}_{1} /{ }^{\circ} \mathrm{C}$ & $T_{\max 1} /{ }^{\circ} \mathrm{C}$ & $\mathrm{FDT}_{1} /{ }^{\circ} \mathrm{C}$ & Second weight loss/\% & $T_{\max 2} /{ }^{\circ} \mathrm{C}$ & $\mathrm{FDT}_{2} /{ }^{\circ} \mathrm{C}$ \\
\hline 0 & 89.7 & 296 & 402 & 486 & 10.3 & 563 & 630 \\
\hline 0.5 & 87.4 & 310 & $308 / 438$ & 495 & 8.3 & 577 & 670 \\
\hline 1 & 91.0 & 320 & $350 / 432$ & 500 & 7.3 & 600 & 640 \\
\hline 3 & 89.4 & 291 & $362 / 400$ & 497 & 8.5 & 589 & 630 \\
\hline 5 & 93.2 & 313 & $348 / 443$ & 490 & 6.0 & 596 & 682 \\
\hline 10 & 94.2 & 305 & $331 / 439$ & 481 & 4.0 & 643 & 685 \\
\hline 20 & 90.5 & 280 & $308 / 426$ & 476 & 5.7 & 612 & 634 \\
\hline
\end{tabular}

IDT initial decomposition temperature (expressed as the temperature where $5 \%$ of mass loss is observed), $T_{\max }$ temperature at the maximum degradation rate, $F D T$ final decomposition temperature

Table 6 TG and DTG data for cured materials containing dicinnamyl sebacate

\begin{tabular}{|c|c|c|c|c|c|c|c|}
\hline Diester/mass $\%$ & First mass loss $/ \%$ & $\mathrm{IDT}_{1} /{ }^{\circ} \mathrm{C}$ & $T_{\max 1} /{ }^{\circ} \mathrm{C}$ & $\mathrm{FDT}_{1} /{ }^{\circ} \mathrm{C}$ & Second mass loss $/ \%$ & $T_{\max 2} /{ }^{\circ} \mathrm{C}$ & $\mathrm{FDT}_{2} /{ }^{\circ} \mathrm{C}$ \\
\hline 0 & 89.7 & 296 & 402 & 486 & 10.3 & 563 & 630 \\
\hline 0.5 & 95.0 & 344 & $366 / 452$ & 494 & 2.9 & 590 & 776 \\
\hline 1 & 90.6 & 314 & $342 / 427$ & 499 & 8.7 & 598 & 645 \\
\hline 3 & 92.0 & 315 & $340 / 425$ & 495 & 8.0 & 602 & 640 \\
\hline 5 & 91.0 & 315 & $345 / 430$ & 492 & 7.0 & 592 & 627 \\
\hline 10 & 92.8 & 305 & $332 / 436$ & 485 & 5.3 & 645 & 695 \\
\hline 20 & 93.8 & 279 & $308 / 425$ & 480 & 5.8 & 628 & 660 \\
\hline
\end{tabular}

IDT initial decomposition temperature (expressed as the temperature where $5 \%$ of mass loss is observed), $T_{\max }$ temperature at the maximum degradation rate, $F D T$ final decomposition temperature

diester content increased. Also, compositions containing diester with higher chain lengths exhibit lower values of storage modulus and glass transition temperature, and higher values of $\tan \delta_{\max }$ height comparing to pure, bulk poly(TRIM) and poly(TRIM)-based materials containing ester with lower chain length.

The values of the heat deflection temperature under load (HDT) and hardness values (HK) are presented in Tables 3 and 4. The small changes in HDT and HK values for the materials containing diesters in the range from 0.5 to 10 mass\% were indicated. The significant drop of HDT values from $110{ }^{\circ} \mathrm{C}$ for bulk, pure poly(TRIM) to 90 and $82{ }^{\circ} \mathrm{C}$ for poly(TRIM) containing 20 mass $\%$ of suitable diester was observed. The drop of HDT values of compositions containing poly(TRIM) and diesters indicated that the materials were more vulnerable to deformation under the specific load at lower temperatures. Also, the same trend was visible for HK values. The reduction in HDT and HK values for higher diester content confirmed obtaining less brittle and more soft materials, which was the result of the disruption and/or weakness of the secondary bonds between poly(TRIM) chains by plasticizer and thus the creation of more space for polymer chain motions.

In addition, the tensile strength $(\delta)$ and percentage elongation $(\varepsilon)$ appeared to be increasing from $60 \mathrm{MPa}$ and $5 \%$ to almost $94-96 \mathrm{MPa}$ and $23-25 \%$ as diesters concentration increased (Tables 3 and 4).

The pure poly(TRIM) decomposed at least in two main stages during pyrolysis (Fig. 2, Tables 5 and 6). However, the asymmetrical shape of DTG curves of pure poly(TRIM) may also suggest that their decomposition runs as multistep processes with two or three steps in the temperature range from c.a. $240{ }^{\circ} \mathrm{C}$ to c.a. $500{ }^{\circ} \mathrm{C}$. The addition of diesters derivatives of 3-phenylprop-2-en-1-ol to poly(TRIM) generally leads to an insignificant increase in IDT temperatures for composition containing small amount of diesters. However, a displacement of the initial decomposition temperature (IDT) of the obtained materials towards lower temperatures as the diester content increased was indicated. As shown in Fig. 2, the materials containing esters decomposed in two main stages. The first stage 
appeared from c.a. $230{ }^{\circ} \mathrm{C}$ to about $500{ }^{\circ} \mathrm{C}$ with $T_{\max 1}$ given in Tables 5 and 6 . Between those temperatures, one non-well-separated DTG signal composed of at least two or three degradation steps was observed. The mass loss under this stage was significant. It ranged from 87.4 to $95.0 \%$. The mass loss was almost independent on the type of diester added and their content. This stage was connected with the decomposition of the ester and carbon-carbon bonds existing in the polymer network. The second decomposition stage was observed at higher temperatures ( $T_{\max 2}$ ) above $550{ }^{\circ} \mathrm{C}$. The mass loss was from 2.9 to $8.7 \%$. It was probably the result of the carbonization process of polymeric residue formed after the first decomposition stage [33].

\section{Conclusions}

The influence of diesters derivatives of 3-phenylprop-2-en1-ol on the properties of bulk poly(TRIM) has been studied. The decrease in the storage modulus $\left(E^{\prime}{ }_{20}^{\circ} \mathrm{C}\right)$, glass transition temperature $\left(T_{\mathrm{g}}\right)$, heat deflection temperature under load (HDT), hardness (HK) and thermal stability, and the increase in the tensile strength $(\delta)$ and percentage elongation $(\varepsilon)$ of the prepared materials, as diester content increases, suggest that diesters act as plasticizers. Based on the obtained results, one can conclude that the presence of diesters in compositions causes the occupation of intermolecular spaces between poly(TRIM) chains and thus the reduction and/or disruption of secondary forces among polymer chains. It leads to changes in the three-dimensional organization of poly(TRIM) and the reduction in the energy needed for molecular montions of polymer chains. As a consequence, the addition of diesters improves the flexibility and elongation and reduces the fragility of the prepared poly(TRIM) materials. In conclusion, due to its influence on the properties of poly(TRIM), diesters could find their place as more environmentally friendly plasticizers, as compared to commercially applied low molecular mass compounds, for other methacrylate cross-linked materials.

Open Access This article is distributed under the terms of the Creative Commons Attribution 4.0 International License (http://creative commons.org/licenses/by/4.0/), which permits unrestricted use, distribution, and reproduction in any medium, provided you give appropriate credit to the original author(s) and the source, provide a link to the Creative Commons license, and indicate if changes were made.

\section{References}

1. BASF The Technical Company: Technical Information TI/ED 2073e;2011.
2. Okay O. Macroporous copolymer networks. Prog Polym Sci. 2000;25:711-79.

3. Hasegawa G, Kanamori K, Nakanishi K, Yamago S. Fabrication of highly crosslinked methacrylate-based polymer monoliths with well defined macropores via living radical polymerization. Polymer. 2011;52:4644-7.

4. Peng L, Zhang J, Li J, Han B, Xue Z, Yang G. Macro- and mesoporous polymers synthesized by a $\mathrm{CO}_{2}$-in-ionic liquid emulsion-templating route. Angew Chem Int Ed. 2013;52:1792-5.

5. Lai JY, Wang TP, Li YT, Tu IH. Synthesis, characterization and ocular biocompatibility of potential keratoprosthetic hydrogels based on photopolymerized poly(2-hydroxyethyl methacrylate)co-poly(acrylic acid). J Mater Chem. 2012;22:1812-23.

6. Kim D, Lee DY, Lee K, Choe S. Effect of crosslinking agents on the morphology of polymer particles produced by one-step seeded polymerization. Macromol Res. 2009;17:250-8.

7. Neto J, Santos W, Lima P, Tanaka S, Tanaka A, Kubota L. A hemin-based molecularly imprinted polymer (MIP) grafted onto a glassy carbon electrode as a selective sensor for 4-aminophenol amperometric. Sens Actuat B Chem. 2011;152:220-5.

8. Yu YY, Chen WC. Transparent organic-inorganic hybrid thin films prepared from acrylic polymer and aqueous monodispersed colloidal silica. Mater Chem Phys. 2003;83:388-95.

9. Grochowicz M, Gawdzik B. Preparation and characterization of porous crosslinked microspheres of new aromatic methacrylates. J Porous Mater. 2013;20:339-49.

10. Schmid A, Kulin LI, Flodin P. Porosity determination of poly(trimethylolpropane trimethacrylate) gels. Macromol Chem Phys. 1991;192:1223-34.

11. Qi T, Sonoda A, Makita Y, Kanoh H, Ooi K, Hitotsu T. Porous properties of poly(glycidyl methacrylate-co-trimethylolpropane trimethacrylate) resins synthesized by suspension polymerization. J Appl Polym Sci. 2002;83:374-2381.

12. Sears JK, Darby JR. The technology of plasticizers. New York: Wiley; 1982.

13. Godwin AD. Plasticizers. In: Craver CD, Carraher CE, editors. Applied polymer science 21st century. Oxford: Elsevier; 2000. p. $157-175$.

14. Faria-Machado AF, Altenhofen da Silva M, Vieira MGA, Beppu MM. Epoxidation of modified natural plasticizer obtained from rice fatty acids and application on polyvinylchloride films. J Appl Polym Sci. 2013;127:3543-9.

15. Nalli S, Cooper DG, Nicell JA. Biodegradation of plasticizers by Rhodococcus rhodochrous. Biodegradation. 2002;13:343-52.

16. Pielichowski K, Świerz-Motysia B. Influence of polyesterurethane plasticizer on the kinetics of poly(vinyl chloride) decomposition process. J Therm Anal Calorim. 2006;83:207-12.

17. Lindström A, Hakkarainen M. Environmentally friendly plasticizers for poly(vinyl chloride)_improved mechanical properties and compatibility by using branched poly(butylene adipate) as a polymeric plasticizer. J Appl Polym Sci. 2006;100:2180-8.

18. Cano JM, Martin ML, Sanchez A, Hernandis V. Determination of adipate plasticizers in poly(vinyl chloride) by microwave-assisted extraction. J Chromat. A. 2002;963:401-9.

19. Yang M, Park MS, Lee HS. Endocrine disrupting chemicals: human exposure and health risks. J Environ Sci Health Part C. 2006;24:183-224.

20. Gupta AP, Ahmad S, Dev A. Modification of novel bio-based resin-epoxidized soybean oil by conventional epoxy resin. Polym Eng Sci. 2011;51:1087-91.

21. Lee KW, Hailan C, Yinhua J, Kim YW, Chung KW. Modification of soybean oil for intermediates by epoxidation, alcoholysis and amidation. Korean J Chem Eng. 2008;25:474-82.

22. Quintana R, Persenaire O, Lemmouchi Y, Sampson J, Martin S, Bonnaud L, Dubois P. Enhancement of cellulose acetate 
degradation under accelerated weathering by plasticization with eco-friendly plasticizers. Polym Degrad Stabil. 2013;98:1556-62.

23. Worzakowska M. Thermal and mechanical properties of polystyrene modified with esters derivatives of 3-phenylprop-2-en-1ol. J Therm Anal Calorim. 2015;121:235-43.

24. Worzakowska M, Ścigalski P. Thermal behavior of cinnamyl diesters studied by the TG/FTIR/QMS in inert atmosphere. J Anal Appl Pyrol. 2014;106:48-56.

25. Grassie N, Scott G. Polymer degradation and stabilisation. Cambridge: Cambridge University Press; 1985

26. Madorsky SL. Thermal degradation of organic polymers. New York: Interscience Publishers; 1964.

27. Schnabel W. Polymer degradation: principles and practical applications. New York: Macmillan; 1981.

28. Thermal Analysis of Polymers. Encyclopedia of polymer science and technology. New York: Wiley; 2005.

29. Grassie N, Murry EJ, Holmes PA. The thermal degradation of poly(-(D)- $\beta$-hydroxybutyric acid): part 2 -changes in molecular weight. Polym Degrad Stabil. 1984;6:95-103.
30. Manikandan Nair KC, Thomas S, Groeninckx G. Thermal and dynamic mechanical analysis of short sisal fibre reinforced polystyrene composites. Compos Sci Technol. 2001;61:2519-29.

31. Rana AK, Mitra BC, Banerjee AN. Short jute fibre-reinforced polypropylene composites: dynamic mechanical study. J Appl Polym Sci. 1999;71:531-9.

32. Calvo S, Escribano J, Prolongo MG, Masegosa RM, Salom C. Thermomechanical properties of cured isophtalic polyester resin modified with poly(e-caprolactone). J Therm Anal Calorim. 2011;103:195-203.

33. Kotaiah Naik D, Monika K, Prabhakar S, Parthasarathy R, Satyavathi B. Pyrolysis of sorghum bagasse biomass into bio-char and bio-oil products. A thorough physicochemical characterization. J Therm Anal Calorim. 2017;127:1277-89. 